\title{
Effect of Holy Basil in Mouthrinses on De Novo Plaque Formation in a Four Day Plaque Regrowth Model with Experimental Gingivitis
}

\author{
${ }^{1}$ Dr Vinita Meena \\ Periodontist \& Private Practisioner, \\ Udaipur, India \\ ${ }^{2}$ Dr Balaji Manohar \\ Professor \& Head, Department of Periodontics, \\ KIDS, Bhubaneshwar, India. \\ ${ }^{3}$ Dr Neema Shetty \\ Professor \& Head, Department of Periodontics \\ $\mathrm{PDCH}$, Udaipur, India
}

\begin{abstract}
To compare the antiplaque and antigingivitis efficacy of $1.25 \%$ holy basil mouthwash to $\mathbf{0 . 2 \%}$ chlorhexidine. 30 systemically healthy subjects where divided in three groups by randomization and were asked to refrain from maintaining mechanical measures for oral oral hygiene for 5 days and used one of the randomly assigned mouthwash (Group I - $0.2 \%$ chlorhexidine, Group II - $\mathbf{1 . 2 5 \%}$ holy basil, Group III sterile water.) Plaque index (PI) and Gingival index (GI) was assessed at day 0 and 5 . Inter group comparison of all the parameters at baseline and 5 day using ANOVA revealed statistically significant result outcome. The results indicated that the $1.25 \%$ holy basil mouthwash has an anti-plaque effect. Hence, the prophylactic benefits of this anti-plaque and anti-gingivitis mouthwash could be beneficial in clinical settings.
\end{abstract}

Keywords:- Chlorhexidine, Plaque, Holiy Basil, Gingivitis Mouthwash.

\section{INTRODUCTION}

To achieve healthy status of periodontium is the main aim of periodontal treatment. Dental plaque and oral biofilms are the main causative factors for maximum periodontal diseases. ${ }^{[1]}$ Dental plaque which is often termed as "Oral biofilm" is defined as the tooth surface bearing the tenacious and soft material that is not easily removable by water rinse. This material is organized complex matrix composing od salivary glycoproteins and ecm products that takes the form of a biofilm on nonshreding niches of the mouth. ${ }^{[2]}$ Therefore, the regular oral hygiene practices is a requisite for proper plaque elimination. ${ }^{[3]}$

Ocimum sanctum is derived from the family Labiatae which is aromatic and considered as the mother or queen of herbs and natural medicine. Richly found 150 species are spread across in two-third region of the world and its 160 species yielding essential oils are densely found in Asia, West Africa and America. Out of the nine type of species

\author{
${ }^{4}$ Dr Aditi Mathur \\ Professor, Department of Periodontics \\ $\mathrm{PDCH}$, Udaipur, India \\ ${ }^{5}$ Dr Barkha Makhijani \\ Professor, Department of Periodontics \\ PDCRC, Udaipur, India \\ ${ }^{6}$ Dr Vivek R Devani \\ Assistant Professor, Department of Periodontics \\ $\mathrm{PDCH}$, Udaipur, India
}

found in India, Ocimum sanctum is most freely found species. ${ }^{[4]}$

The holy basil is used in gingivitis and periodontitis because of its wide range of properties. The immune modulatory, anti-inflammatory, anti-plaque, anti-gingivitis and anti-oxidant like properties proves this mother of earth herb to be beneficial for gingival health. ${ }^{[5]}$

Among the above mentioned properties, its antioxidant nature provides protection and shielding from radiation induced damage and also helps repairing process of if the damage is caused. ${ }^{[6]}$ Its ability to directly act on COX-2 inhibition makes it a potent herb against inflammation. ${ }^{[4]}$ Chlorhexidine is a gold standard mouth rinse product often used as control for comparing the efficacy of the any other antimicrobial agents. ${ }^{[7,8]}$

The aim of the present study to compare the antiplaque and anti-gingivitis efficacy of $1.25 \%$ holy basil mouthwash to $0.2 \%$ chlorhexidine and placebo.

\section{MATERIALS \& METHOD}

A single blind controlled clinical trial was conducted in 30 volunteers of age 18 to 22 years with chronic marginal gingivitis at Pacific Dental College, Debari, Udaipur, Rajasthan. The institution students were the studY volunteers. Informed consent was obtained and the study timeline was explained to all the volunteers.

The products used in the present study were:

Holy basil mouthwash,

$>$ Commercially available chlorhexidine $[0.2 \%]$ mouthwash

$>$ Sterile water. All of the three mouth rinses were standardized and dispensed in masked opaque bottles. 


\section{A. Indigeneous Preparation of mouthwash}

$500 \mathrm{~g}$ of dry tulsi leave powder soaked in $500 \mathrm{ml}$ of water and $500 \mathrm{ml}$ of $95.5 \%$ absolute ethanol for 3 days and then heated to $40^{\circ} \mathrm{c}$ until the volume was reduced to a third. Finally holy basil mouthwash $1.25 \%$ was prepared $(125 \mathrm{ml}$ of extract in $100 \mathrm{ml}$ of distill water) and dispensed in the bottles containing $250 \mathrm{ml}$.

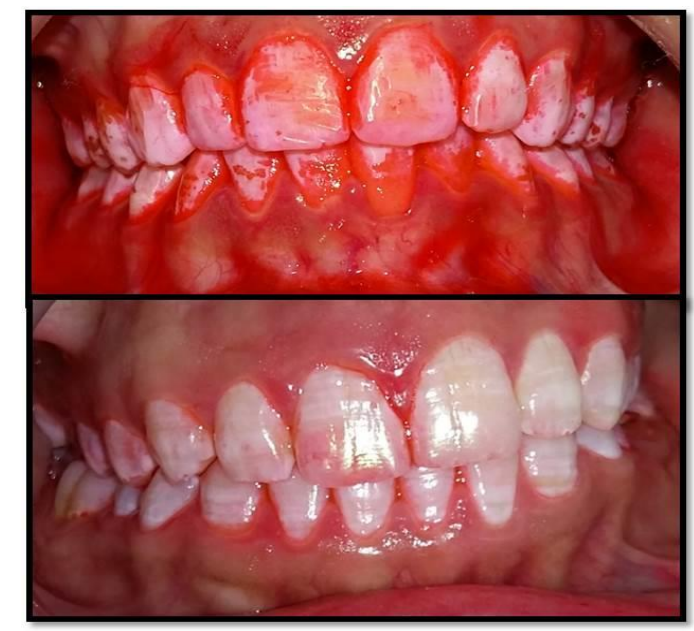

Fig 1:- Baseline and day 5 PI evaluation

\section{B. Inclusion Criteria}

Subject with a minimum of 20 natural teeth with a gingival index score (Loe and Sillness) between 1.1 to 2.0. Subject willing to maintain the continuity of appointment.

\section{Exclusion Criteria}

Subject who underwent non- surgical periodontal therapy in the past three months. History of last three months of antibiotics consumption interfering plaque formation. Presence of any extensive bridges or prosthetic constructions, crowns or restorations and orthodontic appliances. Allergic to any mouth wash.

\section{Study design}

The experimental trial was commenced with the plaque retention models for 4 days. Baseline evaluation begin with recording of Turesky et al. [1970] modification of Quigley and Hein [1962]. ${ }^{[9]}$ This Index used 3\% erythrosine dye (Fig 1) and gingival index was recorded followed by scaling. The Gingival index is used to include volunteers with a gingival index score (Leo and Sillness) between 1.1 to 2.0 in the study as well as to check induce experimental gingivitis. The volunteers were advised to discontinue any mechanical oral hygiene measures during the study period.

The volunteers randomly divided in three groups; Group I: 10 volunteers received $0.2 \%$ chlorhexidine mouthwash using $10 \mathrm{ml}$ of solution for $30 \mathrm{sec}$ twice daily for 4 days.

Group II: 10 volunteers received $1.25 \%$ holy basil mouthwash using $10 \mathrm{ml}$ of solution for $30 \mathrm{sec}$ twice daily for 4 days.

Group III: 10 volunteers received sterile water using $10 \mathrm{ml}$ of solution for $30 \mathrm{sec}$ twice daily for 4 days.
On $5^{\text {th }}$ day appointment, the re-recording of indices allowed to reinstate the routine oral hygiene procedures scores of the plaque re-growth and gingival index score. And they were subjected to statistical analysis. Statistical analysis was performed anova test and test $\mathrm{p}>0.05$ consider significant.

\section{RESULTS}

\begin{tabular}{|c|c|c|c|c|}
\hline Sample & $\begin{array}{c}\text { Mean PI } \\
\text { Day 1 }\end{array}$ & $\begin{array}{c}\text { Mean PI } \\
\text { Day 5 }\end{array}$ & $\begin{array}{c}\text { Mean } \\
\text { Diff. }\end{array}$ & $\begin{array}{c}\text { P } \\
\text { value }\end{array}$ \\
\hline Chlorhexidine & $2.24 \pm 0.49$ & $1.57 \pm 0.44$ & 0.67 & $<0.001$ \\
\hline Holy Basil & $2.24 \pm 0.57$ & $1.77 \pm 0.40$ & 0.47 & $<0.05$ \\
\hline Placebo & $2.24 \pm 0.72$ & $2.66 \pm 0.46$ & -0.42 & $<0.02$ \\
\hline ANOVA & $\mathrm{p}>0.05$ & $\mathrm{P}<0.05$ & & \\
\hline
\end{tabular}

Table 1:- Baseline and $5^{\text {th }}$ Day comparison of PI scores

\begin{tabular}{|c|c|c|c|c|}
\hline Sample & $\begin{array}{c}\text { Mean GI } \\
\text { Day 1 }\end{array}$ & $\begin{array}{c}\text { Mean GI } \\
\text { Day 5 }\end{array}$ & $\begin{array}{c}\text { Mean } \\
\text { Diff. }\end{array}$ & $\begin{array}{c}\text { P } \\
\text { value }\end{array}$ \\
\hline Chlorhexidine & $1.02 \pm 0.14$ & $1.11 \pm 0.14$ & -0.09 & 0.13 \\
\hline Holy Basil & $1.02 \pm 0.06$ & $1.05 \pm 0.10$ & -0.03 & 0.20 \\
\hline Placebo & $1.02 \pm 0.06$ & $1.12 \pm 0.11$ & -0.10 & 0.01 \\
\hline ANOVA & $\mathrm{p}>0.05$ & $\mathrm{p}>0.05$ & & \\
\hline
\end{tabular}

Table 2:- Baseline and $5^{\text {th }}$ Day comparison of GI scores

Thirty subjects completed the study. ANOVA test showed no statistical significant difference between mean of PI scores in the three groups at base line [p>0.05]. In the chlorhexidine and holy basil group, PI showed significant decrease from baseline to day 5 and there was increase mean of PI scores in the placebo group on day 5 compare to baseline. Results were conclusive of the mean difference in PI values from baseline to $5^{\text {th }}$ day to be higher for the placebo rinse [-0.42] and comparatively lower for holy basil [0.47]. The paired $t$ test showed a statistically significant decrease in the PI chlorhexidine compare holy basil and placebo. (Table-1).

In all the groups, GI showed increase from baseline to $5^{\text {th }}$ day. In the chlorhexidine and holy basil group, GI showed non-significant $(p \leq 0.05)$ increase from baseline to day 5 and there was increase mean of GI scores in the placebo group on day 5 compare to baseline is significant. (Table-2).

The differences obtained in the current study between the independent solutions demonstrated statistically nonsignificant in terms of chlorhexidine and holy basil as compared to the placebo. The statistical comparison of chlorhexidine and holy basil was statistically nonsignificant suggesting of both having a similar antigingivitis clinical efficacy. 


\section{DISCUSSION}

Bacterial plaque initiates gingival inflammation. Which if left untreated, progress to periodontal disease. Supra-gingival plaque plays an important role in prevention of gingival inflammation. Mechanical plaque control is efficacious in removing the bacterial plaque. ${ }^{[10]}$ Chemical plaque control measures are therefore used as an adjunctive measure to reach the area inaccessible to mechanical plaque control. ${ }^{11]}$ In 1979, MacGregor and Rugg-Gurm suggested that niches of tooth surfaces receive little or no attention during the brushing process. ${ }^{[12]}$ However, speaking about chemical plaque control measures, chlorhexidine continues to remain the 'gold standard' among all type of mouth washes till date. ${ }^{[11]}$ But long term use cause side effect.

Essential oil-containing rinses are popular next to chlorhexidine. ${ }^{[13,14]}$ One of the major set-back of essential oil rinses is the patient non-acceptance in regards to unpleasant taste. This has led the researchers to quest for an anti-plaque and anti-gingivitis agent that is safe, ideal and having favorable patient acceptance. The clinical trial of herbal mouthwash was undertaken in the current study using a four day plaque model. This type of method is useful in evaluating the inhibitory property of the mouthwash on plaque regrowth in the oral environment that has been used by various researchers. ${ }^{[15]}$

Chlorhexidine, being the gold standard, was found to be more efficacious in our study in comparison to holy basil mouth rinse. However; our study was not in accordance with the study undertaken by Hosamane $\mathrm{M}$ et al that evaluated antiplaque property. ${ }^{[5]}$ Agarwal et al in his study concluded highest antibacterial activity of holy basil. He compared various concentrations of holy basil in an invitro study against Streptococcus mutans and stated $4 \%$ to be the most potent. ${ }^{[16]}$

The development of gingival inflammation is observed to be less in holy basil than in chlorhexidine. The comparison of current study cannot be made with other study from literature as the study design is unique. However, the well-known side-effect of Chlorhexidine, i.e. staining of teeth and restoration, alteration of taste sensation and development of resistant microorganisms, may limit the long-term use of chlorhexidine. ${ }^{[5]}$ The holy basil herbal mouthwash could be potential alternative. In addition, tulsi is easily available, cost effective, with lesser known side effects on its use, potent anti-oxidant and culturally acceptable which can be used in clinical setting for long time use.

\section{CONCLUSION}

The literature supports anti-inflammatory and antioxidant action of holy basil giving significant results for clinical use. The current study is one of such attempt to evaluate the unique plaque model settings. Potentially, the supragingival action of mouthwash is recommended by the findings of this study. However; its subgingival application, long term use, larger sample size with longer follow up period study are recommended.

\section{REFERENCES}

[1]. Socransky SS, Haffajee AD. Dental biofilms: Difficult therapeutictargets. Periodontol 2000 2002;28:12-55.

[2]. Claydon NC. Current concepts in toothbrushing and interdental cleaning. Periodontol 2000 2008;48:10-22.

[3]. Menon L, Ramamurthy J. New vistas in plaque control. IOSR J DentMed Sci 2014;13:64-8.

[4]. Prakash P, Gupta N. Therapeutic uses of Ocimum sanctum Linn (Tulasi) with a note on eugenol and its pharmacological actions: A short review. Indian J Physiol Pharmacol 2005;49:125-31.

[5]. Hosamane M, Acharya AB, Vij C, Trivedi D, Shetty SB, Thakur SL. Evaluation of holy basil mouthwash as an adjunctive plaque control agent in a four day plaque regrowth model J Clin Exp Dent 2014;6:e4916.

[6]. ${ }^{1}$ Uma Devi P, Ganasoundari A. Modulation of glutathione and antioxidant enzymes by Ocimum sanctum and its role in protection against radiation injury. Indian J Exp Biol 1999;37:262-8.

[7]. Loesche WJ. Antimicrobials can they be effective? In: Guggenheim B, editor. Cariology today. Zurich: Karger; 1984. p. 293-300.

[8]. Emilson CG. Potential efficacy of chlorhexidine against mutans streptococci and human dental caries. J Dent Res 1994;73:682-91.

[9]. Quigley G, Hein J. Comparative cleansing efficiency of manual and power brushing. J Am Dent Assoc 1962;65:26-9.

[10]. De la Rosa MR, Guerra JZ, Johnson DA, Radike AW. Plaque growth and removal with daily tooth brushing. J Periodontol 1979;50:661-4.

[11]. Jones CG. Chlorhexidine: Is it still the gold standard? Periodontol 2000 1997;15:55-62.

[12]. MacGregor DM, Rugg-Gurm AJ. A survey of tooth brushing sequence in children and young adults. J Periodontal Res 1979;14:225-30.

[13]. Gordon JM, Lamster IV, Seiger MC. Efficacy of Listerine antiseptic in inhibiting the development of plaque and gingivitis. J Clin Periodontol 1985;12:697704.

[14]. DePaola LG, Overholster CD, Meiller TF, Minah GE, Niehaus C. Chemotherapeutic inhibition of supragingival dental plaque and gingivitis development. J Clin Periodontol 1989;16:311-5.

[15]. Addy M, Willis L, Moran J. Effect of toothpaste rinses compared with chlorhexidine on plaque formation during a 4-day period. J Clin Periodontol 1983;10:89-9.

[16]. Agarwal P, Nagesh L, Muralikrishnan. Evalation of the antimicrobial activity of various concentrations of tulsi extract against Streptococcus mutans: An in vitro study. Indian J Dent Res 2010;21:367-9. 